\title{
Editorial
}

\section{Peak Alpha Frequency and Cognitive Performance}

\author{
Ram Lakhan ${ }^{1}$ \\ ${ }^{1}$ Department of Health and Human Performance, Berea College, \\ Berea, Kentucky, United States
}

J Neurosci Rural Pract 2020;11:513-513

I have read this article with great interest. The authors of this paper added new information on the previously established, positive relationship between peak alpha frequency (PAF) and cognitive performance that PAF is favorably associated with reading comprehension in healthy people. ${ }^{1,2}$ This information has tremendous clinical implications in the areas of cognitive dysfunction. Some study have indicated varied associations of PAF with developmental stages. ${ }^{3}$ However, such research is very limited. Thus, it demonstrates a greater need for more research to observe the relationship of PAF with various cognitive dysfunctions and disorders including various types and levels of dementia, traumatic brain injury, developmental disorders, and substance use disorders. ${ }^{4}$

The implications of this research could be extremely valuable in planning interventions for people with developmental disabilities. There are multiple intellectual tests available, which can estimate the cognitive abilities and concurrent functioning level of an individual. Most of the time in this population, the interventional planning of the professionals is based on the current level of functioning of the individual. However, expected outcomes vary because there is no estimation of how much an individual can grasp. Often, behavior problems in this population mislead the estimation of expected outcomes. In some situations, professionals are clueless on whether an individual with developmental disabilities has more scope of improving their reading comprehension ability or if he/she has achieved their optimum. This uncertain understanding of outcome estimation leads to poor intervention.
If future research can establish a type of scale between PAF and reading comprehension, it could be estimated, by PAF values, how much reading comprehension an individual could acquire. Comprehension is directly associated with expression and processing skills in people with developmental disabilities. A PAF value found through an electroencephalography test can provide a level of reading comprehension ability in people with developmental disabilities. That can be tremendously helpful in planning appropriate interventions and improving their overall comprehension.

\section{Conflict of Interest}

None declared.

\section{References}

1 Rathee S, Bhatia D, Punia V, Singh R. Peak alpha frequency in relation to cognitive performance. J Neurosci Rural Pract 2020;11(3):416-419

2 Angelakis E, Lubar JF, Stathopoulou S. Electroencephalographic peak alpha frequency correlates of cognitive traits. Neurosci Lett 2004;371(1):60-63

3 Angelakis E, Lubar JF, Stathopoulou S, Kounios J. Peak alpha frequency: an electroencephalographic measure of cognitive preparedness. Clin Neurophysiol 2004;115(4):887-897

4 Dickinson A, DiStefano C, Senturk D, Jeste SS. Peak alpha frequency is a neural marker of cognitive function across the autism spectrum. Eur J Neurosci 2018;47(6):643-651
Address for correspondence Ram Lakhan, Department of Health and Human Performance, Berea College, Berea, Kentucky, United States

(e-mail: ramlakhan15@gmail.com).
DOI https://doi.org/

$10.1055 / \mathrm{s}-0040-1713716$

ISSN 0976-3147.
(C2020 Association for Helping Neurosurgical Sick People
License terms

(요 (1) $\Theta \circledast$ 